\title{
Randomized trials assessing calcium supplementation in healthy children: relationship between industry sponsorship and study outcomes
}

\author{
Nancy Nkansah*, Thao Nguyen, Hoda Iraninezhad and Lisa Bero \\ University of California-San Francisco, 155 North Fresno Street Suite 224, Fresno, CA 93701, USA
}

Submitted 28 November 2007: Accepted 18 November 2008: First published online 3 March 2009

\begin{abstract}
Objective: To explore the relationship between industry sponsorship of Ca supplementation studies in healthy children and study outcomes.

Design: An electronic search for published randomized controlled trials (RCT) was conducted. We collected data on study design features aimed at reducing bias, statistical significance of results, authors' conclusions and financial sponsorship of study. We used Fischer's exact test to examine associations between sponsorship and study results and conclusions.

Subjects: Healthy children between the ages of 9 and 18 years.

Results: Nineteen trials met our inclusion criteria. Seventeen out of nineteen studies reported a statistically significant improvement of supplementation on bone mineral density. Subjects in eight of the seventeen studies had a baseline daily Ca intake of $800-1300 \mathrm{mg}$. There was no significant association between study design features and the results or conclusions of the studies. Three studies received government funding, two of which $(66.7 \%)$ concluded in favour of additional supplementation. Sixteen studies were either industry-funded or had mixed industry funding, thirteen $(81 \cdot 3 \%)$ of which had a conclusion supporting Ca supplementation in children. There was no significant association between study sponsorship and authors' conclusions.

Conclusions: The majority of RCT assessing the effects of Ca supplementation in healthy children are industry-funded and support $\mathrm{Ca}$ supplementation. The clinical significance of the outcomes measured in Ca supplementation studies should be considered when examining associations between study design and results. Further non-industry funded research is needed to thoroughly assess the impact of funding on authors' conclusions in nutrition research.
\end{abstract}

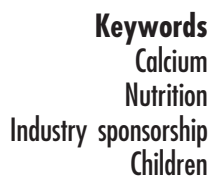

The importance of adequate $\mathrm{Ca}$ intake has been supported on both global (e.g. FAO) and national levels. Guidelines have been published by multiple organizations outlining nutritional recommendations regarding $\mathrm{Ca}$ intake. The Finnish Nutrition Recommendations recommend daily $\mathrm{Ca}$ intake of $900 \mathrm{mg}$ for adolescents ${ }^{(1)}$. The Australian National Health and Medical Research Council recommends a range of $800-1200 \mathrm{mg} / \mathrm{d}$ (age-dependent) for Australian adolescents ${ }^{(2)}$. Other organizations, such as the US Institute of Medicine/National Academy of Sciences and the UN FAO, recommend daily intake as high as $1300 \mathrm{mg}^{(3-5)}$. Depending on location, the average daily baseline consumption of $\mathrm{Ca}$ in adolescents ranges from $340-460 \mathrm{mg}$ (in geographic locations where inadequate nutrition is common) ${ }^{(6,7)}$ to $750-1000 \mathrm{mg}$ (in geographic locations with better access to adequate nutrition) ${ }^{(8-10)}$. With such variation in daily Ca consumption, the question of the effectiveness of $\mathrm{Ca}$ supplementation in healthy children has been studied.

Multiple studies have been published evaluating the effectiveness of $\mathrm{Ca}$ supplementation on bone mineral density (BMD) and dental health in pre-teen and adolescent children ${ }^{(11)}$. These studies have yielded conflicting results. A recent Cochrane Collaboration systematic review evaluated the effect of $\mathrm{Ca}$ supplementation on BMD and concluded that such supplementation has little effect on BMD. The only site with a significant increase in BMD was the upper limb. This effect translated into a $1.7 \%$ greater increase in BMD in the supplemented groups compared with non-supplemented groups. The review does not support the use of Ca supplementation in healthy children as a public health intervention ${ }^{(12)}$.

Industry sponsorship of research is associated with outcomes that favour the sponsor ${ }^{(13-17)}$. This trend has 
held true for studies published recently in the nutrition literature $^{(14,18,19)}$. To date, no studies have examined the association of study characteristics, such as sponsorship, with clinical outcomes of studies evaluating the effectiveness of $\mathrm{Ca}$ supplementation in healthy children between the ages of 9 and 18 years. Thus the present study explores the relationship between industry sponsorship of $\mathrm{Ca}$ supplementation studies conducted in healthy children and study results and conclusions.

\section{Experimental methods}

\section{Identification of studies for inclusion}

We searched MEDLINE and the Cochrane database for randomized controlled trials (RCT) evaluating Ca supplementation in children published between January 1966 and June 2006. Ca supplementation was defined as use of any type of Ca supplement in addition to baseline $\mathrm{Ca}$ intake from the diet. Search terms included: calcium, calcium supplementation, milk, dairy products, bone density, bone mineral density, osteoporosis, fracture, dental, teeth, caries, tooth, and lactose intolerance. We also reviewed the contents of selected peer-reviewed nutrition and paediatric journals (Journal of the American College of Nutrition, American Journal of Clinical Nutrition, Pediatrics, Osteoporosis International, Journal of Bone and Mineral Research, Bone, European Journal of Clinical Nutrition, Journal of the American Dietetic Association and British Journal of Nutrition). References of articles selected from these searches were also reviewed for inclusion.

Articles identified from the initial search were selected by reviewing the abstract and/or the study for the following inclusion criteria: (i) studies reporting a randomized controlled (RCT) design; (ii) those including healthy children between the mean ages of 9 and 18 years in the study population; (iii) children with no co-morbid disease states; (iv) study duration of at least 6 months; and (v) those evaluating $\mathrm{Ca}$ effectiveness on BMD. Studies published in any language were included.

Excluded articles included non-RCT designs (e.g. reviews, commentaries, editorials or letters), those less than 6 months in duration, those including non-healthy subjects (e.g. children with coexisting gastrointestinal disease states, co-morbid disease states such as diabetes and juvenile arthritis, or drug-induced disease states) and studies focused on follow-up after the withdrawal of $\mathrm{Ca}$ supplementation.

\section{Study evaluation}

Articles meeting inclusion criteria were examined individually by three reviewers (study investigators: H.I., T.N. and N.N.) and subsequently coded using a standard instrument. The following categories were coded: (i) study type (placebo-controlled trial, comparative trial, cross-over trial); (ii) study design characteristics aimed to reduce bias (randomization, intention-to-treat, follow-up, blinding); (iii) sample size; (iv) mean age; (v) study population characteristics (nationality, economic status, co-morbid disease states, history of lactose intolerance, patients on treatments that effect bone metabolism); (vi) type of oral supplementation (milk, tablets, powder, dairy foods, nondairy foods); (vii) whether supplementation met current FAO recommendations of $1300 \mathrm{mg} / \mathrm{d}^{(5)}$; (viii) whether baseline Ca intake was less than the $1300 \mathrm{mg} / \mathrm{d}$ recommendation of the $\mathrm{FAO}^{(5)}$; (ix) whether baseline $\mathrm{Ca}$ intake was less than the $800-1300 \mathrm{mg} / \mathrm{d}$ recommended by US, Chinese, Australian, Finnish and FAO recommendations $^{(1,2,4,5,20)}$; (x) institutional affiliation of all authors; (xi) country where study was conducted; (xii) outcome measures; (xiii) results; (xiv) adverse events (if reported); (xv) funding source(s); (xvi) role of sponsor; (xvii) disclosed financial ties of authors; and (xviii) authors' conclusion (whether the authors recommended Ca supplementation, did not recommend Ca supplementation or had a neutral conclusion). Standards on how to code each element were defined prior to the coding process. Each reviewer extracted details from the articles independently. After independent review, all three reviewers met to reconcile the results of the coding, and discrepancies were resolved by reviewing the original article and establishing consensus.

\section{Study design characteristics aimed at reducing bias}

Each study was coded for randomization, use of intention-to-treat analysis, subject follow-up of greater than $75 \%$ and blinding of investigators, statisticians and/or subjects. Coding of such variables is standard in Cochrane systematic reviews as a means to minimize bias and to guide study interpretation ${ }^{(21)}$.

\section{Results and conclusions of studies}

Results for each study were coded based on whether the study reported a statistically significant effect (in either primary or secondary outcomes). If a study found a statistically significant result in a bony region (e.g. hip, spine, forearm), the study was coded as having a statistically significant effect. Studies with measurements from multiple regions were coded as having a statistically significant result if the study found at least one bony region to have a statistically significant change. Results were nominally coded as statistically significant or not.

The study conclusion was evaluated on whether the authors recommended $\mathrm{Ca}$ supplementation (in addition to baseline $\mathrm{Ca}$ intake), did not recommend Ca supplementation or had a neutral conclusion on Ca supplementation for children. Authors' study conclusion was coded independent of the statistical significance of the results and was determined by reading and interpreting the tone of the conclusions. 
Financial sponsorship of study/financial ties of authors Financial sponsorship of studies and financial ties of authors were evaluated based on statements in acknowledgements, potential conflict of interest statements and/or footnotes. Financial sponsorship was characterized as: (i) industry-funded, defined as including dairy, nutritional supplement and/or pharmaceutical industry; (ii) nonindustry funded, defined as including governmental agencies with no industry association (e.g. US National Institutes of Health, universities, non-profit organizations); (iii) mixed funding, including a combination of both industry and non-industry funding; and (iv) none disclosed. If the study received no industry sponsorship but stated that Ca supplements (e.g. milk, Ca tablets) were provided by industry, the study was coded as not receiving industry funding. However, if the paper noted that the industry sponsor provided financial funding in addition to supplements, then the study was coded as receiving industry funding. Explicit statements regarding potential financial ties of all authors were evaluated as well.

\section{Statistical analysis}

All elements of the study were coded, entered into a spreadsheet and analysed by a statistician who was blinded to the variable labels and study hypothesis. Potential subgroup analyses (geographic location (e.g. cultural/ custom/nutritional differences), stratification based on age (tweens: 9-12 years $v$. teens: 13-18 years), type of Ca supplementation) and sensitivity analyses (assessing heterogeneity of studies) were identified a priori; these were to be conducted depending on the variability in study results.

Study elements for which no variability was noted are reported using descriptive statistics. Fischer's exact test, assuming $\alpha=0.05$ and $80 \%$ power to detect an existent difference, was used to analyse variability found between study sponsorship and outcomes. Computations were performed using the SAS statistical software package version 9.1 (SAS Institute, Cary, NC, USA).

\section{Results}

A total of 7442 publications were retrieved. Of these, 7310 did not meet inclusion criteria based on initial review of study abstracts. The full-text versions of the remaining 132 publications were assessed for final review, of which nineteen met all inclusion criteria (see Fig. 1). Publications included were published between 1992 and 2006. A total of 3469 children participated in the studies, and the mean age was $11 \cdot 1$ years. All included studies evaluated bone health (BMD, bone mineral content or fracture rate); no studies that met the inclusion criteria evaluated dental health (development of caries, tooth decay, etc). In addition, during the coding process, all trials reporting and evaluating lactose intolerance were excluded due to the extensive

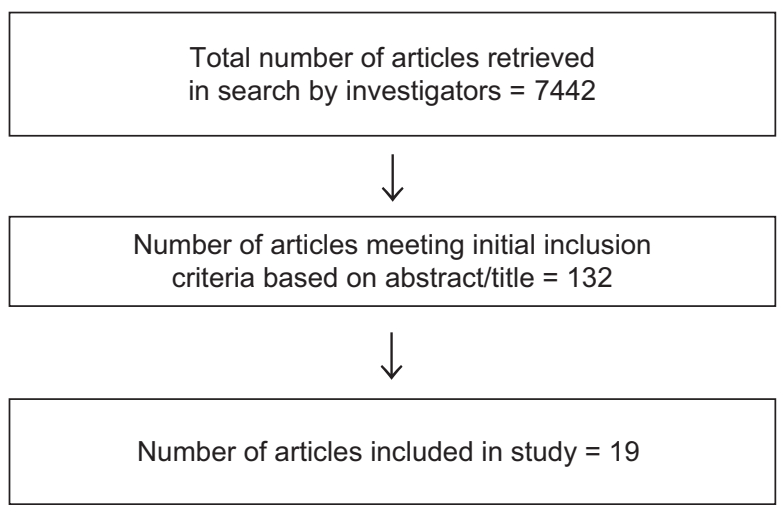

Fig. 1 Flow diagram for inclusion of articles in the study

heterogeneity observed in study design and because the duration of these studies was less than 6 months.

Table 1 shows the characteristics of each included study ${ }^{(6-10,22-35)}$. Seven studies included children from-low income countries. Fourteen out of nineteen studies $(73 \cdot 7 \%)$ were placebo-controlled clinical trials. All studies stated they were randomized. However, only six of them (31.6\%) included a description of randomization. Ten out of nineteen studies $(52 \cdot 6 \%)$ were double-blinded and fifteen studies $(78.9 \%)$ reported follow-up of greater than $75 \%$ after initiation of treatment. Four out of the nineteen studies $(21 \cdot 1 \%)$ utilized an intention-to-treat analysis. There was no association between study design characteristics and the results or conclusions of the studies.

As shown in Table 2, seventeen of the nineteen studies $(89 \cdot 5 \%)$ reported a statistically significant effect of $\mathrm{Ca}$ supplementation on BMD. Of the seventeen studies showing a statistically significant effect, all studies reported a baseline daily $\mathrm{Ca}$ intake of less than the FAO recommendation of $1300 \mathrm{mg}$. Eight of the seventeen (47.1\%) studies reported a baseline daily Ca intake between 800 and $1300 \mathrm{mg}$. The two studies that reported a statistically insignificant effect were sponsored by the dairy industry. There was not enough variability in study results to test for an association between study sponsorship and results.

As shown in Table 3, of the nineteen studies, fifteen (78.9\%) had conclusions that suggested support of $\mathrm{Ca}$ supplementation, one $(5 \cdot 3 \%)$ deemed supplementation as unnecessary and three $(15 \cdot 8 \%)$ had a neutral conclusion on whether supplementation was necessary. Of the three non-industry funded studies, two (66.7\%) had authors that concluded in favour of additional supplementation. Sixteen studies were either industry-funded or received mixed funding, thirteen $(81.3 \%)$ of which had a favourable author conclusion for Ca supplementation in children. There was no significant association between type of study sponsorship and authors' conclusion $(P=0.53)$. 


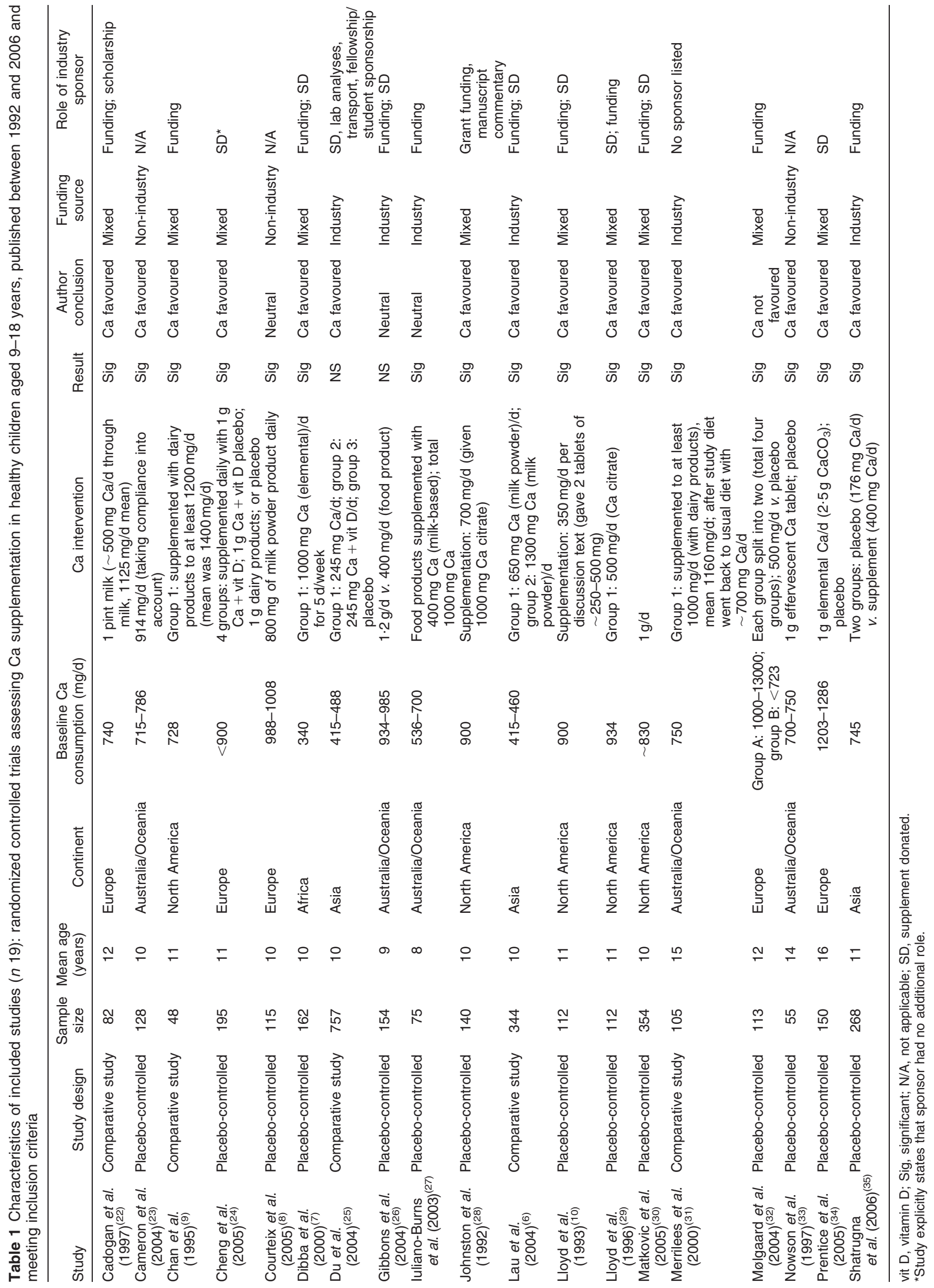


Table 2 Study funding source by statistical significance of bone mineral density results: randomized controlled trials ( $n$ 19) assessing Ca supplementation in healthy children aged 9-18 years, published between 1992 and 2006 and meeting inclusion criteria

\begin{tabular}{|c|c|c|}
\hline Study & Industry funding/mixed funding & Non-industry funding \\
\hline With no statistically significant result & 2 & 0 \\
\hline With statistically significant results & 14 & 3 \\
\hline
\end{tabular}

Table 3 Study funding source by authors' conclusion: randomized controlled trials $(n 19)$ assessing Ca supplementation in healthy children aged 9-18 years, published between 1992 and 2006 and meeting inclusion criteria

\begin{tabular}{lcc}
\hline Conclusion & Industry funding/mixed funding & Non-industry funding \\
\hline Not recommending Ca supplementation & 3 & 1 \\
Recommending Ca supplementation & 13 & 2 \\
\hline
\end{tabular}

\section{Discussion}

We were unable to draw conclusions regarding the association of study characteristics and the results of $\mathrm{Ca}$ supplementation studies conducted in healthy children because almost all of the included studies were favourable towards Ca supplementation. Eight of the seventeen $(47 \cdot 1 \%)$ studies showing statistically significant effects of Ca supplementation were conducted in healthy children with daily $\mathrm{Ca}$ intake over $800 \mathrm{mg}$. Thus, these studies concluded that $\mathrm{Ca}$ supplementation was efficient even if baseline $\mathrm{Ca}$ intake was adequate. Furthermore, almost all $(84 \cdot 2 \%)$ of the studies were industry-sponsored. Thus, there was little variability in study results or sponsorship.

The effect of sponsorship on study outcome has been well documented in the literature. Recipients of industrysupported grants tend to publish research and give advice that favours the sponsor ${ }^{(13)}$. A recent article by Lesser et al. $^{(18)}$ evaluated a wide range of studies examining the health effects of three commonly consumed beverages (soft drinks, juice and milk) and concluded that industry funding may bias conclusions in favour of sponsors' products in the area of nutrition research. Although no statistically significant association between funding source and outcomes was identified in the present study, $81.3 \%$ of industry-funded studies and $66.7 \%$ of government-funded studies reported favourable conclusions that supported Ca supplementation.

Our study has several limitations. First, there is wide variability in how study design and methodology is reported. Only in the past 5-10 years has improved reporting of study characteristics become standard practice in the scientific literature, particularly financial disclosure statements from authors ${ }^{(36)}$. Industry sponsorship was not explicitly defined and the extent of industry involvement in study design and analysis was not reported in most of the trials analysed. It is not known if industry representatives were involved in study data collection and analysis, or only provided the $\mathrm{Ca}$ supplements/dairy products with no additional involvement. More detailed disclosure of study design and methodology may have helped tease out certain study characteristics that may have been associated with study conclusions.

Our study did not evaluate the clinical significance of the reported results in each study. If the authors found a statistically significant improvement in BMD in only one bony region and concluded that Ca supplementation had a positive effect, this was documented as a favourable result. For example, in one of the included studies, Shatrugna et al. found after 6 months of Ca supplementation that there was a statistically significant increase in BMD at the neck of the femur but nowhere else ${ }^{(35)}$. Although we coded this as a statistically significant result, we did not assess the clinical significance. In addition, when coding whether authors' conclusions were in favour or not in favour of Ca supplementation, we assumed that the authors' conclusion referred to the type of $\mathrm{Ca}$ supplementation used in their study.

Adequate $\mathrm{Ca}$ intake is important, but the effects of $\mathrm{Ca}$ supplementation are less clear. Although the studies we included were conducted in healthy children, seven of the seventeen $(41 \cdot 2 \%)$ studies with statistically significant results were conducted in children with baseline daily Ca intake below $800 \mathrm{mg}$. Winzenberg et al. recently published a Cochrane systematic review evaluating the literature on $\mathrm{Ca}$ supplementation in children, concluding that $\mathrm{Ca}$ supplementation has little effect on BMD and is not recommended in healthy children ${ }^{(12)}$. Winzenberg et al.'s review differs from the present study in that it evaluated the clinical significance of the reviewed studies' results. When combining the data from the included studies, Winzenberg et al. found only a small increase in BMD at the upper limb; this result was deemed to be clinically insignificant in terms of fracture rate reduction. Winzenberg et al.'s study included eleven out of the nineteen studies included herein. It is not possible to objectively assess whether reported authors' conclusions would be altered if clinical significance were taken into account.

There are a limited number of published RCT, especially non-industry funded studies, in healthy children aged 9-18 years evaluating the effect of Ca supplementation on BMD. With the small sample size ( $n$ 19), 
sixteen of which had some form of industry funding while three had no industry involvement, most studies concluded in favour of $\mathrm{Ca}$ supplementation regardless of funding type. Given recent concern over conflict of interest in academic research, it would be beneficial to have a larger sample of non-industry funded studies in this area. An additional study with a larger sample size, including a similar proportion of industry and nonindustry funded studies, could be conducted to validate our findings.

From a policy perspective, it is difficult to conclude if dairy industry funding is associated with study results in the area of Ca supplementation in healthy children and nutrition research. Further studies in this area will contribute to our understanding of validity in nutrition research.

\section{Conclusion}

No conclusion can be drawn about the association between study characteristics and outcomes among RCT assessing Ca supplementation in healthy children aged 9-18 years. The clinical significance of the outcomes measured in studies of Ca supplementation should be considered when examining associations between study design and results. Further non-industry funded research is needed to thoroughly assess the impact of funding on authors' conclusions in the area of nutritional research.

\section{Acknowledgements}

Sources of funding: The present study was supported in part by funding through the California Tobacco-Related Disease Research Program (TRDRP) grant entitled 'Corporate Strategies: Design, Conduct, Publication of Research 2004 (Cycle XIII) 13RT-0108H' awarded to L.B. Conflicts of interest: The authors do not have conflicts of interest to disclose. Author contributions: N.N. - coding, data analysis, manuscript writing/revising, study advisor; T.N. and H.I. - coding, data analysis, manuscript writing; L.B. manuscript writing/revising, study advisor, securing funding. Acknowledgements: We would like to acknowledge Peter Bacchetti, PhD (Professor, UCSF) for statistical analysis; Amy Andres (Librarian, UCSF-Fresno) and Kathy Hoesman (Medical Librarian, Kaiser Permanente-Fresno Medical Center) for assistance in retrieving articles relevant to our study; and Grace Carlson (Administrative Assistant, UCSFFresno) for her assistance throughout the study period.

\section{References}

1. National Nutrition Council (2005) Finnish Nutrition Recommendations. Helsinki: National Nutrition Council.

2. National Health and Medical Research Council (2003) Dietary Guidelines for all Australians. Canberra: NHMRC.

3. US Department of Health and Human Services, National Institutes of Health, National Institute of Child Health and Human Development (2006) Milk Matters. http:// www.nichd.nih.gov/publications/pubs/upload/strong_bones_ lifelong_health_mm.pdf (accessed March 2007).

4. Food and Nutrition Board, Institute of Medicine (1997) Dietary Reference Intakes for Calcium, Phosphorus, Magnesium, Vitamin D, and Fluoride. Washington, DC: National Academy Press.

5. Food and Agriculture Organization of the United Nations/ World Health Organization (2002) Calcium. In Human Vitamin and Mineral Requirements. Report of a Joint FAO/ WHO Expert Consultation, pp. 151-171. Rome: FAO.

6. Lau EM, Lynn H, Chan YH, Lau W \& Woo J (2004) Benefits of milk powder supplementation on bone accretion in Chinese children. Osteoporos Int 15, 654-658.

7. Dibba B, Prentice A, Ceesay M, Stirling DM, Cole TJ \& Poskitt EM (2000) Effect of calcium supplementation on bone mineral accretion in Gambian children accustomed to a low-calcium diet. Am J Clin Nutr 71, 544-549.

8. Courteix D, Jaffré C, Lespessailles E \& Benhamou L (2005) Cumulative effects of calcium supplementation and physical activity on bone accretion in premenarchal children: a double-blind randomized placebo-controlled trial. Int $J$ Sports Med 26, 332-338.

9. Chan GM, Hoffman K \& McMurry M (1995) Effects of dairy products on bone and body composition in pubertal girls. J Pediatr 126, 551-556.

10. Lloyd T, Andon MB, Rollings N, Martel JK, Landis JR, Demers LM, Eggli DF, Kieselhorst K \& Kulin HE (1993) Calcium supplementation and bone mineral density in adolescent girls. JAMA 270, 841-844.

11. Lanou AJ, Berkow SE \& Barnard ND (2005) Calcium, dairy products, and bone health in children and young adults: a reevaluation of the evidence. Pediatrics 115, 736-743.

12. Winzenberg TM, Shaw K, Fryer J \& Jones G (2006) Calcium supplementation for improving bone mineral density in children. Cochrane Database Syst Rev issue 2, CD005119.

13. Nestle M (2001) Food company sponsorship of nutrition research and professional activities: a conflict of interest? Public Health Nutr 4, 1015-1022.

14. Levine J, Gussow J, Hastings D \& Eccher A (2003) Authors' financial relationships with the food and beverage industry and their published positions on the fat substitute Olestra. Am J Public Health 93, 664-669.

15. Barnes DE \& Bero LA (1998) Why review articles on the health effects of passive smoking reach different conclusions. JAMA 279, 1566-1570.

16. Barnes DE \& Bero LA (1997) Scientific quality of original research articles on environmental tobacco smoke. Tob Control 6, 19-26.

17. Lexchin J, Bero LA, Djulbegovic B \& Clark O (2003) Pharmaceutical industry sponsorship and research outcome and quality: systematic review. BMJ 326, 1167-1170.

18. Lesser LI, Ebbeling CB, Goozner M, Wypij D \& Ludwig DS (2007) Relationship between funding source and conclusion among nutrition-related scientific articles. PLoS Med 4, e5.

19. Vartanian L, Schwartz M \& Brownell K (2007) Effects of soft drink consumption on nutrition and health: a systematic review and meta-analysis. Am J Public Health 97, 667-675.

20. US Department of Health and Human Services (2006) Dietary Guidelines for Americans. http://www.health.gov/ DietaryGuidelines/ (accessed March 2007).

21. Higgins JPT \& Green S (editors) (2008) Cochrane Handbook for Systematic Reviews of Interventions Version 5.0.1, Updated September 2008. http://www.cochrane-handbook. org (accessed January 2009).

22. Cadogan J, Eastell R, Jones N \& Barker ME (1997) Milk intake and bone mineral acquisition in adolescent girls: randomized, controlled intervention trial. BMJ $\mathbf{3 1 5}$, $1255-1260$. 
23. Cameron MA, Paton LM, Nowson CA, Margerison C, Frame M \& Wark JD (2004) The effect of calcium supplementation on bone density in premenarcheal females: a co-twin approach. J Clin Endocrinol Metab 89, 4916-4922.

24. Cheng S, Lyytikäinen A, Kröger H et al. (2005) Effects of calcium, dairy product, and vitamin D supplementation on bone mass accrual and body composition in 10-12-y-old girls: a 2-y randomized trial. Am J Clin Nutr 82, 1115-1126.

25. Du X, Zhu K, Trube A, Zhang Q, Ma G, Hu X, Fraser DR \& Greenfield H (2004) School-milk intervention trial enhances growth and bone mineral accretion in Chinese girls aged 10-12 years in Beijing. Br J Nutr 92, 159-168.

26. Gibbons MJ, Gilchrist NL, Frampton C, Maguire P, Reilly PH, March RL \& Wall CR (2004) The effects of a high calcium dairy food on bone health in pre-pubertal children in New Zealand. Asia Pac J Clin Nutr 13, 341-347.

27. Iuliano-Burns S, Saxon L, Naughton G, Gibbons K \& Bass SL (2003) Regional specificity of exercise and calcium during skeletal growth in girls: a randomized controlled trial. J Bone Miner Res 18, 156-162.

28. Johnston CC, Miller JZ, Slemenda CW, Reister TK, Hui S, Christian JC \& Peacock M (1992) Calcium supplementation and increases in bone mineral density in children. $N$ Engl J Med 327, 82-87.

29. Lloyd T, Martel JK, Rollings N, Andon MB, Kulin H, Demers LM, Eggli DF, Kieselhorst K \& Chinchilli VM (1996) The effect of calcium supplementation and Tanner stage on bone density, content and area in teenage women. Osteoporos Int 6, 276-283.
30. Matkovic V, Goel PK, Badenhop-Stevens NE et al. (2005) Calcium supplementation and bone mineral density in females from childhood to young adulthood: a randomized controlled trial. Am J Clin Nutr 81, 175-188.

31. Merrilees MJ, Smart EJ, Gilchrist NL, Frampton C, Turner JG, Hooke E, March RL \& Maguire P (2000) Effects of diary food supplements on bone mineral density in teenage girls. Eur J Nutr 39, 256-262.

32. Mølgaard C, Thomsen BL \& Michaelsen KF (2004) Effect of habitual dietary calcium intake on calcium supplementation in 12-14-y-old girls. Am J Clin Nutr 80, 1422-1427.

33. Nowson CA, Green RM, Hopper JL, Sherwin AJ, Young D, Kaymakci B, Guest CS, Smid M, Larkins RG \& Wark JD (1997) A co-twin study of the effect of calcium supplementation on bone density during adolescence. Osteoporos Int 7, 219-225.

34. Prentice A, Ginty F, Stear SJ, Jones SC, Laskey MA \& Cole TJ (2005) Calcium supplementation increases stature and bone mineral mass of 16- to 18-year-old boys. J Clin Endocrinol Metab 90, 3153-3161.

35. Shatrugna V, Balakrishna N \& Krishnaswamy K (2006) Effect of micronutrient supplement on health and nutritional status of schoolchildren: bone health and body composition. Nutrition 22, 1 Suppl., S33-S39.

36. Altman DG, Schulz KF, Moher D, Egger M, Davidoff F, Elbourne D, Gøtzsche PC \& Lang T; CONSORT GROUP (Consolidated Standards of Reporting Trials) (2001) The revised CONSORT statement for reporting randomized trials: explanation and elaboration. Ann Intern Med 134, 663-694. 